\title{
The Strategic Role of Technology in a Good Society
}

\section{Philip Brey}

This is a preprint version of the following article:

Brey, P. (2017). The strategic role of technology in a good society. Technology in Society. Advance online publication. https://doi.org/10.1016/j.techsoc.2017.02.002

The aim of this paper is to investigate the proper role of technology in a good society, and to define criteria for assessing the extent to which technologies contribute to the quality of society. General theories of the role of technology in a good society are currently missing, I

claim. So are good assessment criteria for the contribution of technologies to a good. This essay intends to fill this void.

Technology has become integral to the fabric of society, and helps to shape its quality. To assess whether and how technologies actually contribute to the quality of society, an overall, integrated framework for such assessments is needed. Such a framework would do three things: (1) define general criteria for the goodness or quality of society; (2) analyze how technologies, and different designs and uses of them, either promote or detract from the goodness of society according to these criteria; (3) contribute to the development of particular ways of designing and using technology that better support the overall quality of society. Such a framework is currently lacking, and it is the aim of this paper to propose one in the context of a discussion of various previously proposed criteria for a good society.

My proposal for an assessment framework will take shape as follows. First, I will propose an account of how technology impacts or "shapes" society. This account will be based on some of the prevailing views in science and technology studies (STS) and the philosophy of technology. Second, I will analyze how such impacts can be related to the goodness of society. I will argue that the goodness of society can be defined in terms of a number of values or ideals, and that impacts of technology can be analyzed as either contributing to, or detracting from, the realization of such values. Third, having established that technologies can positively or negatively affect the realization of values, I ask what the values of a good society are, and I will arrive at a proposal for five key values for a good society. In a last section, finally, I will analyze how technological products could be designed and used to support and uphold these values, and hence to thus contribute to a good society. I conclude that it is possible to develop approaches for the development as well as the assessment of technologies that contribute to a good society, and that it is imperative for us to do so.

\section{How Technology Shapes Society}

To understand how technology influences the goodness of a society, we first need to understand how technology has social impacts. This is a somewhat controversial topic, since very different theoretical perspectives exist on the interaction between technology and society that lead to different conceptions of social impacts. In what follows, I will propose a particular viewpoint on this matter that finds support in empirical research in the field of science and technology studies that has been undertaken in the past thirty years. According to this viewpoint, technology, which is itself shaped by society, actively shapes society by influencing the way in which people behave, the way in which social roles, relations and institutions are constructed, and the manner in which culture manifests itself. It does not do so in a deterministic fashion; its influence is co-determined by social and material contexts and interpretive frameworks that govern the use of the technology. Nevertheless, both within 
and across contexts, it is often possible to identify a role for technology in the shaping of society (MacKenzie \& Wajcman, 1999; Quan-Haase, 2013).

By technology I mean the products of engineering design: devices, systems, procedures and methods that are developed by engineers and used in society for practical ends. It is these products of engineering that, when used in a particular social context, generate social impacts. In understanding the relation between technological products and social impacts, it is imperative to avoid two extreme perspectives: those of technological neutrality and of technological determinism (Winner, 1977; Illies \& Meijers, 2009). The neutrality view is that technological products themselves are neutral with respect to consequences. It is rather the uses to which they are put in particular contexts that determine social consequences. Take for example a hammer. It can be used for carpentry, but also to scratch one's back or commit murder. Clearly, the argument goes, hammers are neutral regarding impacts, and its impacts are generated by choices in use.

The neutrality view only works for simple and versatile tools like hammers, however. As I have argued previously ([reference to own work not given due to double-blind peer review]), technological products are typically complex machines and devices with dedicated functions and uses. A microwave oven, for example, does not have many uses besides heating food, and a radio does not have many uses besides transmitting radio broadcasts. The highly specialized functionality of machines seriously limits the range of plausible uses to which they can be put and thereby restricts the range of social impacts that can be generated. Many technological devices are moreover used in a limited range of social contexts in which it makes sense to use them. This fixation of the uses and social contexts means that the technological devices often generate a limited range of social impacts that can be identified and studied. This finding undermines the neutrality view, since it follows that there are often reliable correlations between technological designs and generated social impacts.

Although there may be tendencies for certain technological products to be correlated with certain social consequences, it does not follow that technological determinism is true. Technological determinism is the view that technological products reliably cause certain social consequences, independently of social context or use. This view is demonstrably false. Social impacts of technology always depend not only on the technological product that is used, but also on the use to which it is put and the social context in which it is used. However, technological products sometimes allow for only a few sensible uses and are only used in a few social contexts, and in such a scenario, it may be possible to identify correlations between the introduction of the technological product and particular social consequences.

In the perspective that I advocate, technological products have causal powers to generate social impacts in the sense that their introduction and use in a particular social setting or class of social settings tends to generate certain social consequences, provided the product is used to benefit from its highly specialized functionality. I have argued previously that technological products influence their social context in two ways: through affordances and constraints ([reference to own work not given due to double-blind peer review]). First, artifacts may afford, enable, allow, induce, stimulate, cause, necessitate or require certain events or states-of-affairs. For example, in vitro fertilization (IVF) techniques allowed a distinction to be made between genetic motherhood and biological motherhood, and consequently required a renegotiation of the social status of motherhood and new social definitions of the social roles that genetic and biological mothers were expected to play. I will say that IVF techniques afford these events and states-of-affairs.

Second, artifacts may constrain, discourage, prevent, prohibit or disallow events or states-of-affairs. For example, speed bumps discourage drivers from speeding, and the heavy balls on (classical) hotel keys discourage people from taking the key with them when they 
leave the hotel (Latour, 1987). In my terminology, the bumps and keys constrain certain events or states-of-affairs from taking place. Note that affordances and constraints are not objective features of artifacts but depend on use and context of use. For instance, the constraint imposed on the taking of keys outside hotels by heavy weights depends not only on the material constitution of the key, but also on the social context (e.g., the fact that people exiting hotels often do not have carts or servants with them to carry things), and on common beliefs and practices (e.g., that carrying the key with one is too inconvenient, or creates a bulge in one's clothing that is unaesthetic). Still, it is useful to attribute the constraint of taking the key with one to the heavy weight, and not the whole context in which it is used. For these weights are still the immediate cause of people not taking their hotel key with them.

Although affordances and constraints of technological products are not objective features of them, they can be correlated with objective material features in them. For example, the physical constitution of speed bumps physically prevents cars from speeding without damage to the car or major inconvenience. The physical procedure of fertilization in IVF affords pregnancies without prior physical intercourse. In a particular context of use, these physical features translate into new social realities (new behaviors, new social arrangements, new perceptions and beliefs) that can be identified as impacts of a technological product.

Social impacts of technology can be identified at different levels of social analysis, including the micro-level of individuals and their interactions, the meso-level of groups and organizations and their interactions, and the macro-level of social structures, cultural systems and social institutions and their dynamics (Misa, 1994). For the study of the role of technology in a good society, which is an issue that plays out at the macro-level, macro-level impacts of technology are obviously the most important to consider. However, micro- and meso-level impacts may also need to be considered in order to properly identify and understand macro-level impacts.

At the micro-level, technological products may influence their immediate context of use in at least three ways. First, they may affect the behavior of users and the social roles and relations that users build in relation to others. For example, the possession of an automobile may influence where people live and what places they visit, and may also signal social status and identity. Second, technological products will not fit every user profile equally well, meaning that some users will not be able to use them well, or not at all, because they lack the required physical characteristics, knowledge, skills, interests, or access to resources. As a consequence, the introduction of a new technological product will affect potential users in different ways, benefiting some while excluding or marginalizing others.

Third, technological products often require the presence of material and social contextual background conditions for them to function well. For example, for automobiles to function well as vehicles for transportation, there must be material and social infrastructure present, such as roads, traffic lights, police, ambulance services, and so forth. The introduction of new technological products will therefore often stimulate the creation of appropriate background conditions for them to function well. This is also a way in which technological products have social impacts. These three types of affordances and constraints, concerning influence on behavior and social roles, selection of user profiles, and selection of material and social background conditions, also play out at the meso-level of groups and organizations.

At the macro-level, finally, technological products and systems also impose material and social background conditions, thereby stimulating certain types of material infrastructure or social organization to occur. For example, a centralized power grid requires a greater form of social organization and centralization than decentralized energy resources systems, because of the requirements for generating and distributing power in such a system. 
Technological products may also stimulate certain social structures and institutional arrangements not by requiring them as background conditions, but by affording or stimulating new social and institutional arrangements by the new functionality offered by the technology. For instance, digital networks have afforded the development of organizations that are more distributed geographically, and have as a consequence enabled a more globalized economy. Similarly, technological products may foster new cultural forms and systems. They have enabled new subcultures that center on technology use or are enabled by it, and they may change cultural values, attitudes and practices by the affordances they generate. For example, birth control pills have arguably aided in the sexual liberation of women and thereby supported a more equal status for women and men.

\section{How Technology Bring About Goodness}

What is a good society? It is a society that has certain qualities that make it good. For example, it has been claimed at various times that a good society is just, is prosperous, and that it has a well-functioning democracy. Some qualities that are used to describe a good society can be quite concrete and specific, whereas others are quite abstract. The abstract qualities that are used to define a good society are generally more fundamental than concrete qualities. For example, some people hold that a good society guarantees a minimum level of welfare to its people, whereas others hold that it should be characterized by equality of opportunity. What both groups can agree on is that a good society is a just society; they merely have different interpretations of what justice consists of. A fundamental characterization of a good society is given by defining the abstract qualities that a society ideally possess.

Such ideal abstract qualities are also called values. Values are ideals that people strive to realize in the real world. For example, if someone embraces freedom as a value, he or she will strive to act to promote conditions in the world that support or uphold people's freedoms. For each value, it is possible in principle to specify satisfaction conditions that should be met for a value to be realized in the real world. Satisfaction conditions are social or physical in nature, or both. Because people may differ on the meaning or content of a particular value, they may however specify different satisfaction conditions for it.

Here are some candidate satisfaction conditions for well-known values:

Justice: social and economic inequalities (in the distribution of social goods) should be arranged so that they are to the greatest benefit to the least advantaged in society, and offices and positions must be open to everyone under conditions of fair equality of opportunity (after Rawls, 1971).

Informational privacy: persons have control over who has access to personal information that pertains to them.

Autonomy: persons have the ability to construct their own goals and values, and are unrestrained in their ability to make choices and plans and to act in ways that are believed by them to help achieve these goals and promote these values (after Dworkin, 1988).

Sustainability: social and economic arrangements are such that they do not do structural damage to ecosystems in ways that deplete natural resources, pollute the environment, and harm the ability of societies to provide for their needs and the wellbeing of their citizens. 
With this conception of values, as abstract ideals that have concrete satisfaction conditions in the real world, it can now be explicated how technologies can contribute to the goodness of society through social impacts. The satisfaction conditions of values can coincide with or correlate positively or negatively with social impacts of technology. For example, solar panels (technology) contribute to social and economic arrangements that do not do structural damage to ecosystems (impact that coincides with a satisfaction condition of sustainability), and in this way contribute to sustainability (value), which, if it is one of the constitutive values of a good society, contributes to a good society. By generating particular impacts, technologies can therefore either harm or stimulate the realization of the satisfaction conditions for particular values.

Through their impacts on society, technologies therefore influence the realization of values in both positive and negative ways. It should now be clear how we can investigate the proper role of technology in a good society. Such an analysis requires an understanding of the values that jointly define a good society, as well as an analysis of how technologies may uphold such values and refrain from harming their realization. In the next two sections, I will investigate candidates for a set of values that define a good society, after which I will investigate how these values may be supported by technology.

\section{Values for a Good Society}

Given the vast amount of literature in political theory and social and political philosophy, it is surprising how little there is that centrally asks the question what defines a good society. Nevertheless, several answers have emerged to this question, which has often been left implicit (West, 2001). Welfarist conceptions hold that a good society is a society in which its citizens are guaranteed, by the state, a minimum level of welfare, material well-being, or access to primary goods, so that they can live fully human lives (Michelman, 1973). Civic republican conceptions hold that the state must ensure that citizens can be free and equal participants in collective governance, which requires that they are given certain rights and primary goods (Sandel, 1996). Capability approaches hold that a good society is one in which it is ensured that citizens enjoy certain fundamental human capabilities that allow them to prosper and have good lives (Sen, 1984; Nussbaum, 2003). Communitarians hold that a good society is one that contains flourishing communities that promote a shared understanding of morality and purpose and mutual trust (Etzioni, 1999).

A limitation of existing approaches to the good society is that they often fail to make a distinction between those qualities of a good society that are constitutive of it and those that are merely instrumental in attaining these constitutive qualities. In theories of value, a common distinction is that between intrinsic and instrumental value (Zimmerman, 2014). For something to be intrinsically valuable, it must have a worth in and of itself. For example, it is thought that persons have a value in and of themselves, meaning that they are not valuable because of particular labor or pleasure that they can provide to others, but are valuable for their own sake. A hammer, in contrast, has instrumental value: it is a means through which other valuable things can be achieved. Clearly, some things can have intrinsic and instrumental value at the same time. A person, for example, has intrinsic value but can also provide instrumental value to others through labor.

If we are to determine the values that define a good society, our striving should be to determine, at a minimum, those values that are most fundamental. Those will be intrinsic values. It is, for example, often held that social order is an important virtue of societies, but social order is clearly an instrumental value, not an intrinsic one. Social order is not desirable for its own sake, but is desirable because of other things it achieves, such as preventing chaos 
and war and fostering cooperation. In what follows, I will examine some candidates for intrinsic values for a good society, as well as some values that I call necessary instrumental values (i.e., values that are instrumental, but that are necessary means for realizing the intrinsic values). Although I believe a good case can be made for them, the candidates I propose are only candidates; a full argument for them is beyond the scope of this paper. The intent of presenting these candidates is rather illustrative, to show what a theory of values for a good society may look like (this section), and then to show how such a normative account of a good society may be used to evaluate technologies for their contribution to a good society (section 4 ).

A first candidate intrinsic value for a good society is well-being. Well-being is clearly something that people find intrinsically valuable, and many may find that nothing more important exists than their well-being and that of others. Philosophical theories of the good often reveal themselves as theories of well-being, thus supporting an intimate connection between well-being and our overall conception of goodness (e.g., Kraut, 2007). Clearly, a society that does not support, directly or indirectly, the well-being of its citizens cannot be a good society. So well-being appears to qualify as one of the intrinsic values of a good society.

Could it be that well-being is the only intrinsic value that a good society should strive to uphold? This idea is supported by certain crude versions of utilitarianism, which hold that the only principle that should govern societies is the maximization of utility. However, even within utilitarianism, it is often recognized that a good society is characterized by at least one other value: that of justice (Mill, 1961/1993). And within utilitarianism, justice is sometimes recognized as a second principle next to the maximization of well-being, although one group of utilitarians, rule utilitarians, often hold that principles of justice are mere means by which well-being can be maximized, and therefore do not hold justice to be an intrinsically valuable goal. I would argue, instead, that justice is best understood as valuable for its own sake. Many people find justice so important that they seem willing to make some sacrifices to overall utility or well-being in order to achieve it. Influential theories of justice, such as John Rawls's (1971), also define justice separately from the maximization of well-being, and allow for trade-offs between justice and overall well-being in a society. I therefore recognize justice as a second intrinsic virtue of a good society.

A third often-mentioned candidate is freedom. It has often been claimed that a good society is a free society, in which citizens have protected rights for the free pursuit of happiness, freedom of thought, freedom of expression, freedom of assembly, and freedom of religion. Freedom is clearly a virtue of a good society. But is it an intrinsic virtue or an instrumental one? A case can be made that it is an instrumental virtue, because freedoms appear to be sought so that people can attain ends other than freedom itself. For example, the right to the pursuit of happiness is a freedom right that has happiness (or well-being) as its goal; the right to this pursuit is only a means towards this end. Let us define a necessary (instrumental) value as one that must be realized in order for a more fundamental, intrinsic value to be realized. Even if freedom is an instrumental value for a good society, it appears to be a necessary value, in that it is arguably difficult to properly attain the intrinsic values of a good society without realization of this particular value.

Democracy is arguably a necessary instrumental value for a good society as well, since it does not appear to be something that people seek for the sake of itself, but rather for other ends. Democracy has been defended as a political system that is better able than others to lead to a good society because it better takes into account the interests, rights and opinions of citizens, and because it has positive effects of the character of citizens. These are instrumental justifications of democracy as a superior institution for promoting a good society. 
Sustainability has also been proposed as a criterion for a good society. It is clearly a necessary virtue of a good society, since without sustainability, well-being will ultimately suffer, and justice suffers as well, since future generations are unjustifiably deprived of goods that are afforded to current generations. Could sustainability be an intrinsic value of a good society? I believe not, since definitions of sustainability commonly refer to well-being or need satisfaction as ends towards sustainability is to contribute. Sustainability is therefore a necessary instrumental value of a good society.

Other values, such as equality, autonomy, friendship, community, trust and privacy, can, I believe, all be defined as either necessary or contingent instrumental values for the support of well-being and justice, or as values that are necessary components of our ideals of well-being or justice. I tentatively conclude, then, that the two highest virtues of a good society are well-being and justice, and that a good society is in addition characterized by a number of necessary instrumental values, that include at least those of freedom, democracy and sustainability, and probably more. Of course, the further interpretation of these values, and the formulation of satisfaction conditions for them, can be done in rather different ways, leading to different conceptions of a good society. In particular, the value of well-being can be interpreted in radically different ways, and may include or exclude all kinds of other values, such as physical excellence, wisdom, artistic expression, friendship, autonomy, community, and others. I will not, however, attempt a further specification of the concept of well-being in the context of this paper.

\section{Technology for a Good Society}

If the above proposal for values for a good society is correct, then technology for a good society can be defined as technology that provides fundamental support for well-being and justice as intrinsic values for a good society, and also upholds necessary instrumental values, including freedom, democracy and sustainability. There are different ways to ensure that technology plays this positive role. First, obviously, the design and development of technology should be recognized as a moment at which political and moral choices are made, and special efforts should be made to ensure that technology development takes into account basic values of a good society. There are several ways to achieve this. A first one is to engage more stakeholders in technology development and design, as is promoted, amongst others, by the European Commission in its advocacy of Responsible Research and Innovation (RRI), which aims to make research and innovation more responsive to society's needs and values (European Commission, 2012). Stakeholder engagement in technology development has a long history. It has been central in STS and technology assessment, which have long advocated a democratization of technology, and in design and development approaches like participatory design and participatory development.

Another approach is that of Values in Design, which tends to includes stakeholders, but which is more specifically focused on supporting designers in including values in design (Van den Hoven, Vermaas \& Van de Poel, 2015). Values in Design approaches hold that designers should explicitly consider values in the design of technological products, and operationalize them as design specifications that they try to realize in design. The most wellknown Values in Design approach is value-sensitive design (Friedman, Kahn \& Borning, 2006). The advantage of Values in Design approaches over regular stakeholder-driven approaches is that they involve an explicit consideration of values, including values that pertain to the good of all, something that is not guaranteed in ordinary stakeholder-inclusive approaches.

A second way of ensuring a positive role of technology in society is to pay systematic attention to its embedding and use. As argued earlier, impacts of technology are not the result 
of technological products and systems in and of themselves, but also of their embedding in particular social and material arrangements and the rules and norms that govern their use. Therefore, whenever a new technology is introduced, there invariably has to be a process of rearranging existing social and material arrangements and introducing and modifying rules and norms so that desired consequences for society are promoted and undesired ones are avoided. At the level of public policy, in particular, it is important to accompany the introduction of new technologies into society by new laws, incentives and initiatives to help ensure positive outcomes for society at large.

Having observed how society can promote desirable values for technology, let us now consider, for each of the five values that were identified to be key to a good society, some of the ways in which technology can uphold them and how it can also harm their realization. Well-being, to start with, is a value that pertains to individual human beings. It is a complex value, since there are many aspects that contribute to well-being, and it is also a partially subjective value, since the criteria for well-being will be different for different people. There is therefore not a simple way in which technology can either foster well-being or harm it. This does not mean that designing technology to support well-being is impossible. It just means that designers must be aware of the multi-faceted nature of well-being and the different conceptions of well-being that exist in society. The problem with current technological products for individual consumers is that they are designed to support specific functions that are believed to satisfy desires and needs of consumers, but that there is no integral consideration of well-being in the development of technological products, both regarding any side-effects of product use and regarding long-term effects on well-being.

It has only been in recent years that designers have explicitly started designing for well-being. I review these efforts in [reference to own work not given due to double-blind peer review]. There, I conclude that although some promising approaches have recently emerged, the whole field is still in its infancy, and major steps still need to be taken to develop rich methodologies that take into account the complexity and person-relativity of conceptions of well-being. I also conclude, however, that designing for well-being is possible, and that much more effort is needed towards such design. Considerations of wellbeing should not only be an issue in the design of consumer products, but also in the design of public infrastructure. Large infrastructural projects now sometimes require a social impact assessment, a review of the expected social effects of such projects. These reviews often consider implications for the quality of life of affected stakeholders, and therefore could be helpful in proper development of such projects.

Design for well-being would consider short-term and long-term, direct and indirect implications of new technologies for key aspects of well-being. What are key aspects of well-being is contested, and may vary from person to person, but typically mentioned components include physical health, various kinds of pleasure (bodily, aesthetic, creative, etc.), desire-fulfillment, autonomy, self-respect, deep personal relationships, security, knowledge, wisdom, virtue and the experience of transcendent meaning. If one were to develop operational definitions of these aspects of well-being (which, admittedly, may be challenging for some of them), it should be possible to assess for technological products and processes whether or not they tend to contribute to them. Of course, such contributions are also dependent on the context of use and on the particular uses these products are put, but that can be taken into consideration in the assessment. Although overall design for well-being is still in its infancy, for some of the key aspects of well-being, such as health, security, autonomy and knowledge, there are already elaborate design approaches that address them in part or in whole.

Let us consider, as an example, the design of a new smartphone. For each of the features and functions of smartphones, and for each of the mentioned dimensions of well- 
being, it can be studied empirically whether and how smartphones positively or negatively contribute to well-being. At its most extreme, this could lead to a reevaluation of smartphones and a questioning of whether they actually make a net positive contribution to well-being in society. More plausibly, however, it could lead to various new design features in them that enhance well-being. Health, for example, can be taken into account not only by designs that mimimize risks of harm through radiation damage, laceration or electric shock, but also by installing hard- and software that discourages or prevents unhealthy ways of using the phone, such as those that have an adverse effect on eyesight, unsafe use in traffic or sprained necks and thumbs. The hard- and software of smartphones could also be designed to better take into consideration the smartphone's for improving personal relationships, knowledge and creativity, and to avoid designs that can undermine such values. Similarly, smartphones could be designed to protect and not harm privacy, which is a key component of autonomy as well as other well-being generally. In this way, all key aspects of well-being could be systematically taken into account in the design of smartphones.

Secondly, let us consider technologies that promote justice. In an earlier publication, I defended John Rawls's principles of justice and applied them to technology ([reference to own work not given due to double-blind peer review]). Rawls focuses on the just distribution of so-called primary social goods: goods that everyone wants to pursue their goals, such as rights, liberties, income and wealth. Just distribution of these goods requires, according to Rawls, that people have an equal opportunity to positions and offices in which such goods can be acquired, and that any unequal distributions of such goods take place in such a manner that the least well off are still better off in such a system than in a system that distributes goods more equally but that may as a result produce less social goods overall. Approaches for just design are, like those for well-being, still in their infancy, although there are approaches that cover aspects of it, notably the approach of Universal Design (Steinfield and Maisel, 2012) which aims at designs of products and environments that can be used by all people. Considerations of justice are also center stage in political critiques of technology and design such as those of Langdon Winner (1995) and Andrew Feenberg (2002).

As I argued in [reference to own work not given due to double-blind peer review], technological products can support justice by being free from bias in the way that they help distribute, or give access to, social primary goods. ${ }^{1}$ Not all products provide such access. For example, an electric toothbrush is rather inconsequential for the distribution of social goods: people do not tend to have access to more liberties, opportunities, income or wealth because they possess electric toothbrushes. On the other hand, a personal computer or smartphone can provide significant advantages to its owner, in providing new opportunities and information that can assist in the acquisition of additional social goods. As Van den Hoven and Rooksby (2008) have argued, information has itself become a social primary good in the information age, so it is vital that people have good access to information technologies. Similarly, access to transportation is important for people as it also provides important opportunities and liberties. It is important that people have adequate access to technological products that have proven value in enhancing social primary goods such as opportunities and liberties.

Such access implies that key technologies that provide access to primary social goods are not biased against certain user profiles by either excluding certain classes of users or by selectively burdening certain classes of users. Technological designs of these key technologies should support universal access. In cases where this is not possible, governments should take extra measures to aid individuals in modifying their user characteristics or background conditions so that they can use these technologies, or to provide

\footnotetext{
${ }^{1}$ I can now add that the same principle applies to natural primary goods, such as health, intelligence and imagination. These goods can also be stimulated or harmed by technological products.
} 
alternative arrangements for them so that they can have access to particular social primary goods. Furthermore, in the design and use of technological infrastructures in society, their indirect consequences for justice should also be taken into account, such as indirect exclusions or uneven creation of new affordances or opportunities that disadvantage certain groups in society.

In part, the just design of new technology is a matter of resource allocation: which technologies get built, and which do not? An unjust scenario is one in which new technologies provide systematic support for some groups in society but not for others. In particular, it is unjust if resources are allocated to develop technologies for those in society who are already well off (in terms of wealth, income, occupation, social status, health and education) and not for those who are worse off. For example, an allocation of (public or public-private) resources to develop costly medical technologies that can only be afforded by a small group is unjust if the same resources could have been allocated to develop medical technologies that help millions. Similarly, an allocation of resources to build agricultural robots that are only useful at large farms disadvantage owners of small farms as it may drive them out of business and also disadvantages farm workers that may be replaced. If no mitigating actions are taken to take account of their interests, such technologies lead to more inequality.

Considerations of justice do not only pertain to which technological products get made, but also how they are designed. Design choices can determine, for example, whether certain user groups get access to the functionalities of a product and whether these functionalities are useful to them. An automated teller machine may be designed to give access to blind persons (using braille, sound and an interface in relief), or it may not. It may be designed to display information in different languages, or it may not. It may only give out larger amounts of cash, or it may also issue smaller amounts for those who need that option. Designs are always made with a particular user in mind: someone with particular physical features, cognitive features, cultural beliefs, values, and interests, who operates in a particular context. Inclusive designs accommodate as many different users are possible and thereby promote fairness and justice. This could also mean that many different versions of the same product are brought to market if it is not possible to accommodate different user interests and profiles in one product.

Next, freedom can become a design criterion for technological products by taking basic freedom rights into consideration and designing products so that they provide affordances for the exercise of such rights and that unnecessary constraints are removed that block their exercise ([reference to own work not given due to double-blind peer review]). For example, the Internet has enabled new ways of communicating and has thereby supported freedom of expression, even in countries in which such freedoms are under pressure. However, internet censorship can undermine these rights, and should therefore only be undertaken with extreme caution. Similarly, it is nowadays recognized that buildings, especially public buildings, should be designed to be accessible to all people and provide adequate access conditions for people with disabilities that limit their mobility.

Fourth, democracy implies that all people in a society are involved in the governance of that society, either directly or indirectly, thought the election of representatives. In a representative democracy, technology should support free and fair elections, and should support separation of branches of government, a free press, and adequate channels of information and communication between government officials and citizens. In a direct democracy, technology should support good procedures for collective decision-making. Sclove (1995) has advocated a set of design criteria for democratic technologies, which include recommendations that technological products include a mixture of individual, communitarian and trans-community technologies, that technologies that establish 
authoritarian relationships are avoided, that technologies should be designed to enable disadvantaged people and groups to participate fully in social life, and that they help secure democratic self-governance by supporting local economic and political self-reliance.

Sustainability, finally, requires that sustainable products are developed that make use of biodegradable or recyclable materials, that are energy-efficient and use renewable energy, and that are embedded in life cycles that are themselves sustainable. Much progress is being made in the development of methodologies for so-called sustainable design or eco-design. Moreover, for large infrastructural projects, environmental impact assessment is available as a methodology for the review of expected environmental effects. Technological products can also be designed to promote sustainable behavior by affording and stimulating sustainable behaviors and constraining unsustainable behaviors ([reference to own work not given due to double-blind peer review]).

\section{Conclusion}

In this essay, I set out to investigate the proper role of technology in a good society and to define criteria for the assessment of technologies for their contribution to the quality of society. I argued that technological products shape society and often have identifiable social impacts. These social impacts translate into positive and negative effects for the realization of values such as justice, freedom and sustainability. I then continued to identify key values for a good society. I argued that key values are well-being and justice, which are the two intrinsic values that characterize a good society. I also identified several necessary, but ultimately instrumental values for a good society, including freedom, democracy and sustainability. Finally, I discussed how the mentioned five values may be supported (and harmed) through the development and use of technology. I concluded for each of these values that there are ways to develop technology to systematically support these values.

In future work, the proposals developed in this paper could be taken further in several ways. First, I realize that more extensive arguments are necessary to defend a particular conception of a good society and the values that are at its core. Second, operationalizations will have to be developed for these values, along with methods of impact assessment to assess how technologies can positively or negatively impact their realization. This could be a combined activity of ethicists and those working in the areas of social impact assessment and technology assessment. Finally, methods of technology development and technology governance will have to be developed that integrate considerations of technologies having positive social value into the development and governance of new technologies. Thus, this paper defines an exciting new research program that could provide genuine benefits for society.

\section{References}

[reference to own work not given due to double-blind peer review]

[reference to own work not given due to double-blind peer review]

[reference to own work not given due to double-blind peer review]

[reference to own work not given due to double-blind peer review]

[reference to own work not given due to double-blind peer review]

Dworkin, G. (1988). The Theory and Practice of Autonomy. Cambridge: Cambridge University Press. 
Etzioni, A. (1999). Debate: The Good Society. The Journal of Political Philosophy, 7(1), 88103.

European Commission (2012). Responsible Research and Innovation: Europe's ability to respond to societal challenges. Luxembourg: Publications Office of the European Union.

Feenberg, A. (2002). Transforming Technology: A Critical Theory Revisited (2 ${ }^{\text {nd }}$ ed.). Oxford University Press.

Friedman, B., Kahn, P., \& Borning, A. (2006). Value Sensitive Design and Information Systems. In P. Zhang \& D. Galletta (eds.), Human-Computer Interaction in Management Information Systems: Foundations, Armonk, NY: M.E. Sharpe, 69-101.

Illies, C, \& Meijers A. (2009). Artefacts without Agency. The Monist, 92(3), 420-440.

Kraut, R. (2007). What is Good and Why: The Ethics of Well-Being. Cambridge, MA: Harvard University Press.

Latour, B. (1987). Science in Action: How to Follow Scientists and Engineers through Society. Cambridge, MA: Harvard University Press.

MacKenzie, D., \& Wajcman, J. (eds.) (1999). The Social Shaping of Technology: How the Refrigerator Got Its Hum, $2^{\text {nd }}$ ed. Milton Keynes, UK: Open University Press.

Michelman, F.I. (1973). Constitutional Welfare Rights: One View of Rawls' Theory of Justice. University of Pennsylvania Law Review, 121(5), 962-1019.

Mill, J.S. (1993). Utilitarianism, On Liberty, Considerations on Representative Government. London: Everyman. Originally published in 1861.

Misa, T.J. (1994). Retrieving Sociotechnical Change from Technological Determinism. In M.R. Smith, \& Leo Marx (eds.), Does Technology Drive History? The Dilemma of Technological Determinism, Cambridge: MIT Press, 115-141.

Nussbaum, M. (2003), Capabilities as Fundamental Entitlements: Sen and Social Justice. Feminist Economics, 9(2/3), 33-59.

Quan-Haase, A. (2013). Technology and Society: Social Networks, Power, and Inequality. Oxford: Oxford University Press.

Rawls, J. (1971). A Theory of Justice. Cambridge, MA: Harvard University Press.

Sandel, M.J. (1966). Democracy's Discontent: America in Search of a Public Philosophy. Cambridge, MA: Harvard University Press.

Sclove, R. (1995). Democracy and Technology. New York: Guilford Press.

Sen, A. (1984). Rights and Capabilities. In A. Sen, Resources, Values and Development, Cambridge, MA: Harvard University Press, 307-324.

Steinfield, M. \& Maisel, J. (2012). Universal Design: Creating Inclusive Environments, Hoboken, NJ: Wiley.

Van den Hoven, J., \& Rooksby, E. (2008). Distributive Justice and the Value of Information: A (Broadly) Rawlsian Approach. In J. van den Hoven, \& J. Weckert (eds.), Information Technology and Moral Philosophy, Cambridge: Cambridge University Press, 376-396.

Van den Hoven, J., Vermaas, P., \& Van de Poel, I. (2015). Handbook of Ethics, Values, and Technological Design. Sources, Theory, Values and Application Domains. Dordrecht, The Netherlands: Springer. 
West, R. (2001). Rights, Capabilities, and the Good Society. Fordham Law Review, 69, 19012000.

Winner, L. (1977). Autonomous Technology. Cambridge, MA: MIT Press.

Winner, L. (1980). Do Artifacts have Politics? Daedalus, 109, 121-136.

Winner, L. (1995). Political Ergonomics. In R. Buchanan \& V. Margolin (eds.), Discovering Design: Explorations in Design Studies, Chicago, University of Chicago Press.

Zimmerman, M. (2014). Intrinsic vs. Extrinsic Value. In E. Zalta (ed.), The Stanford Encyclopedia of Philosophy, URL: http://plato.stanford.edu/entries/value-intrinsicextrinsicl. 